\title{
Escolas teóricas do processo de internacionalização: uma visão epistemológica
}

LÚCIA DE FÁtIMA LÚCIO GOMES DA COSTA

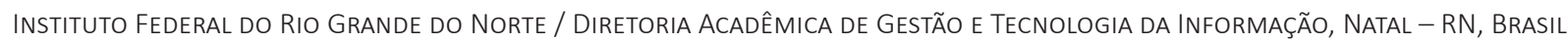

Miguel EduARdo Moreno AÑez

Universidade federal do Rio Grande do norte / Programa de Pós-Graduação em Administração, Natal - RN, Brasil

ANDERSON LUIZ REZENDE MOL Universidade federal do Rio Grande do Norte / Programa de Pós-Graduação em Administração, Natal - RN, Brasıl

Thiago dos Santos AzeVedo Damasceno Universidade Federal do Rio Grande do Norte / Programa de Pós-Graduação em Administração, Natal - RN, Brasil

\section{Resumo}

A internacionalização como fenômeno organizacional em permanente evolução teórica e gerencial criou a oportunidade de construção desta investigação, cujo objetivo é analisar a evolução do conceito de internacionalização por meio das escolas econômicas e comportamentais que a abordam. É apresentada uma revisão da literatura sobre as escolas que desenvolveram estudos empíricos e que postulam modelos de análise sobre a forma de internacionalização das empresas no mundo e, por último, apresenta-se o conceito de born global, que se refere à evolução do fenômeno de internacionalização. Assim, demonstra-se a mudança de paradigma na forma de perceber o processo de internacionalização dos pontos de vista pragmáticos e teóricos.

Palavras-chave: Internacionalização. Conceitos. Epistemologia da internacionalização.

\section{Theoretical schools of the internationalization process: an epistemological view}

\section{Abstract}

This research was based on Internationalization as an organizational phenomenon in permanent theoretical and managerial developments It aims to analyze the evolution of the concept of 'internationalization' through economic and behavioral schools. A literature review is presented, discussing the schools that develop empirical studies and postulate analysis models on methods for internationalization of companies in the world. Finally, the concept of born global is presented, considering the development of the internationalization phenomenon. The article depicts the paradigm shift in how the internationalization process is seen pragmatically and theoretically.

Keywords: Internationalization. Concepts. Epistemology of internationalization.

\section{Escuelas teóricas internacionalización del proceso: una visión epistemológica}

\section{Resumen}

La internacionalización, como fenómeno organizacional en permanente evolución teórica y gerencial, creó una oportunidad para la elaboración de esta investigación, cuyo objetivo es analizar la evolución del concepto de internacionalización a través de las escuelas económicas y comportamentales que abordan. Se presenta una revisión de la literatura sobre las escuelas que desarrollaron estudios empíricos y que postularon modelos de análisis sobre la forma de internacionalización de las empresas en el mundo y, por último, se introduce el concepto de born global, que se refiere a la evolución del fenómeno de la internacionalización. Así, se demuestra el cambio de paradigma en la manera de percibir el proceso de internacionalización bajo los puntos de vista pragmático y teórico.

Palabras clave: Internacionalización. Conceptos. Epistemología de la internacionalización. 


\section{INTRODUÇÃO}

A dinâmica dos mercados e os movimentos propiciados pela mudança de comportamento da sociedade nos últimos 60 anos refletem no ambiente organizacional o surgimento de novas formas de gestão e de fenômenos emergentes. A busca por melhorias e por práticas que conduzam à promoção de vantagem competitiva sustentável tem sido a realidade dos executivos e dos estudiosos em estratégia organizacional (HITT, 2005).

A internacionalização é um desses fenômenos emergentes, que assume nas últimas décadas um caráter basilar nas estratégias organizacionais. Dito de outro modo, a internacionalização não é mais vista como um processo secundário vislumbrado em um futuro estratégico das empresas e sim como um pressuposto da natureza estratégica das empresas globais com atuação no mercado nacional e/ou internacional.

A reflexão sobre a formatação das estratégias com vistas ao desempenho operacional é pauta dos estudos desde a década de 50. A exemplo disso, podem ser citados Edith Penrose (1959), com a teoria do crescimento da firma; e Chandler (1962), um dos precursores da teoria contingencial e estrutural. Esses estudos apresentavam abordagem sobre as capacidades organizacionais por meio dos seus recursos sinalizando a perspectiva de interação com o ambiente (mercado), o que demonstra uma ruptura com as teorias do comércio internacional, orquestradas, até então, por teóricos da economia clássica como Adam Smith (1776) e David Ricardo (1817).

Essas pesquisas merecem destaque na formatação das investigações futuras relacionadas com as estratégias internacionais. As abordagens sobre equilíbrio econômico pautadas nas dimensões organizacionais estabelecem análises de amplo nível de alcance e de recorrente verificabilidade, presente na maioria dos estudos sobre o tema. Uma abordagem teórica, relativamente recente sobre essas dimensões, é a Visão Baseada em Recursos (Resource-Based View - RBV), que tem como pressuposto a análise do posicionamento estratégico da organização com base em vantagens competitivas dos seus recursos.

A partir da década de 80 e de forma mais significativa na década de 90, o fenômeno internacionalização passou a apresentar características de processo de mudança evolutiva e conceitual. O que a princípio era tido como uma estratégia deliberada, que ocorria de forma gradativa ou eventual, passa a ser um aporte estratégico desde o nascimento da organização, o que dá origem à terminologia "nascidas globais" ou global born como comumente são chamadas as empresas que nascem deliberadamente formatadas para atender o mercado internacional (KNIGHT e CAVUSGIL, 2004; OVIATT e McDOUGALL, 1994).

Desse modo, percebe-se que o fenômeno internacionalização é um conceito em evolução e que o caráter exploratório de muitas pesquisas relacionadas com o tema corresponde à própria natureza do constructo (CANTWELL, 2014). Apesar de novas perspectivas teóricas acerca do fenômeno, percebe-se que estudos mais recentes retomam algumas categorias de análises investigadas desde a década de 50.

O processo estratégico internacional não depende apenas de especificidades do mercado, de vantagens particulares da firma ou de um arranjo de fatores que se manifestam segundo critérios objetivos de decisão e escolha dos modos de entrada. A implementação unilateral pelo entrante no mercado estrangeiro não garante que a firma possa obter sucesso no mercado internacional, haja vista que a decisão por uma dessas vantagens comparativas poderá comprometer o resultado $O$ processo inclui também a escolha de relacionamentos que produzam maior vantagem a acessos a recursos valiosos em toda sua cadeia, como clientes, fornecedores, distribuidores e agências governamentais (JOHANSON e MATTSSON, 1988; ROOT, 1994).

Percebe-se que o conjunto de fatores que afetam o desempenho internacional das empresas é bastante variado e complexo. E apesar de o tema ter sido vastamente pesquisado, ainda não há um consenso em relação aos modelos explicativos e de predição acerca do desempenho organizacional de empresas internacionalizadas.

Embora os estudos não tratem diretamente da mudança paradigmática do fenômeno da internacionalização, são utilizadas variáveis também abordadas em pesquisas consideradas marcos teóricos dessa mudança; como a pesquisa realizada por Knight e Cavusgil (2004), que analisam empresas nascidas globais por intermédio de fatores relativos a inovação e capacidades organizacionais (recursos).

Diante do exposto, o presente artigo tem como objetivo apresentar uma construção teórica sobre a convergência dos estudos e constructos considerados como intervenientes no fenômeno da internacionalização das empresas, observando a criação do conceito e de sua evolução. Para tanto, foram identificados estudos representativos de duas correntes de pesquisa: gestão estratégica - visão baseada em recursos e negócios internacionais -; correntes econômica e comportamental. 


\section{TEORIA DO CICLO DO PRODUTO DE VERNON (1966)}

Essa teoria explica que, em virtude do desenvolvimento do ciclo do produto, o mercado oferece condições para ampliações de negócios, o que, por sua vez, dá origem às multinacionais. Logo, a cada estágio do ciclo de vida do produto, a empresa passa a assumir nova fase no processo de internacionalização.

A organização, desse modo, passa por um processo gradual: a princípio a empresa realiza operações fora do seu entorno com um produto geralmente inovador e que Ihe proporcione vantagem competitiva por meio da exportação. No segundo estágio, a organização passa pela fase de crescimento do produto. As exportações são consolidadas até ser realizado o investimento direto no país estrangeiro. No terceiro estágio, ocorre a saturação da produção. Assim, é desenvolvida a padronização do processo produtivo, o qual será transferido para países de custo menor. No quarto e último estágio, o declínio ocorre quando a demanda do país do estágio inicial é inferior a oferta produzida.

Embora a teoria siga criteriosamente a essas fases, de fato observadas pelas empresas, apresenta, segundo o autor, baixo poder preditivo, visto que há um número bastante significativo de variáveis não considerado pelo modelo.

A abordagem proposta por Vernon (1966) inicia uma percepção economicista da internacionalização, aprimorada por Buckley e Casson (1998), por meio das operações internacionais.

\section{TEORIA DAS OPERAÇÕES INTERNACIONAIS - BUCKLEY E CASSON (1998)}

De acordo com o modelo, o mercado pode ser atendido por meio de quatro formas: empresas domésticas; subsidiárias e multinacionais; empresas nacionais que comercializam produtos importados; e por importação direta de multinacionais. Assim, a teoria visa explicar métodos de previsão de atendimento de empresas multinacionais.

Nesse caso, são definidas dimensões necessárias ao reconhecimento de cada mercado: a) localização das plantas produtivas; e b) a propriedade da produção. Na primeira dimensão, a empresa escolhe uma posição estratégica para cada estágio de produção, ou seja, a decisão pela localização depende da relação de menor custo produtivo. Na segunda dimensão, por sua vez, considera-se o local de produção como estático, assim os insumos são internacionalizados incorporados a sua cadeia de produção. Dessa maneira, existe uma tendência perene de empresas buscarem sempre mercados que possam ofertar insumos a preços mais competitivos.

A teoria das operações internacionais é aprimorada pela leitura do Paradigma Eclético, de Dunning, que observa aspectos de posicionamento e vantagem competitiva da firma.

\section{A TEORIA DO PARADIGMA ECLÉTICO}

Dunning (1980), com o Paradigma Eclético, buscou realizar uma junção da abordagem econômica com a explicação de outras variáveis intervenientes no processo. Assim, o autor procurou compilar as teorias que observam aspectos como localização, competição monopolista, internacionalização e custos de transação, para desenvolver o paradigma de ownership localization internalization (OLI).

De acordo com o autor, o modelo envolve determinantes de produção internacional, assim ele é utilizado mais para essa avaliação do que propriamente para a análise de padrões de internacionalização. $O$ autor ressalta ainda que, diante dessa condição, o modelo tem pouca capacidade preditiva.

O Paradigma Eclético busca explicar os padrões de internacionalização por meio de três variáveis:

a) ownership (vantagem de propriedade): análise da organização em posicionamento estratégico (PORTER, 1989) superior às concorrentes no mercado exterior. São considerados principalmente ativos intangíveis na determinação dessa vantagem, tais como: tecnologia; recursos humanos; informações; marcas; patentes; processos produtivos, dentre outros; 
b) localization (vantagem da localização): vantagem que pode ser desenvolvida pela empresa se considerados aspectos determinados de cada país ou região onde a empresa está localizada. São geralmente considerados aspectos como custos de mão de obra, impostos domésticos, infraestrutura, entre outros;

c) internalization (internalização): capacidade de a organização internalizar vantagens de propriedades adquiridas em mercados externos. Assim, o autor sugere que quando os custos de transação são superiores aos de incorporação, a organização tende a se internalizar no mercado, passando, então, a atuar como fabricante.

A teoria eclética define como condição necessária para o desenvolvimento da última variável o amadurecimento das duas primeiras. Dessa forma, a organização poderá fazer o investimento direto no estrangeiro.

Apesar de sintetizar as demais teorias econômicas, essa teoria não leva em consideração o comportamento do exportador. A abordagem eclética da produção internacional é base fundamental ao desenvolvimento estratégico dos custos de transação e de informações e à observação de oportunidades de negócios geradas pelos agentes. É importante frisar que a pesquisa recente sobre internacionalização tem dedicado esforço para relacionar as capacidades organizacionais com a performance internacional de firmas que atuam na arena internacional, considerando variáveis também comportamentais (BIANCHI e WICKRAMASEKERA, 2016; CIRERA, MARIN e MARKWALD, 2015; LOVE, ROPER e ZHOU, 2016; NAVARRO-GARCÍA, ARENASGAITÁN, RONDÁN-CATALUÑA et al., 2016). É por essa razão que essa teoria é considerada um modelo multiteórico, cujas características principais se devem ao fato de a decisão pelo ingresso internacional ser balizada por teorias de negócios internacionais, custos de transações e pela Visão Baseada em Recursos (RBV).

Dessa forma, observa-se que cada teoria agrega contribuições importantes ao processo de internacionalização, que tem como base o posicionamento voltado para mudança e amparado pelas teorias de estratégia empresarial.

A abordagem do Paradigma Eclético de Dunning tanto busca observar aspectos da abordagem econômica da internacionalização, como abre espaço para a abordagem comportamental. Essa análise é iniciada pela Escola Nórdica de Uppsala, cujos autores apresentam um modelo incremental da internacionalização.

\section{O PROCESSO DE INTERNACIONALIZAÇÃO SEGUNDO A ESCOLA NÓRDICA DE UPPSALA}

Na década de 70, na Universidade de Uppsala, Suécia, sucedida pela Escola Nórdica de Negócios Internacionais, começaram a surgir diversos estudos sobre o processo de internacionalização das empresas suecas (JOHANSON e VAHLNE, 1977; JOHANSON E WIEDERSHEIM-PAUL, 1975).

Johanson e Vahlne (1977) propõem um modelo baseado em observações empíricas realizadas em estudos na Universidade de Uppsala, bem como no paradigma comportamental. Os dados mostram que as empresas suecas geralmente desenvolvem as operações internacionais em pequenos passos em vez de realizarem grandes investimentos em momentos esporádicos. Geralmente, as empresas começam a exportar para outros países via agentes, posteriormente estabelecem subsidiária de vendas e, eventualmente, iniciam a produção no país hospedeiro (JOHANSON e VAHLNE, 1977). De acordo com pesquisas recentes, apesar de considerarem a possibilidade de processos mais rápidos, o gradualismo proposto pela escola seria uma forma conservadora para a identificação do campo empírico no estudo da performance internacional (HUANG, WU, LU et al., 2016; MAIS, CARVALHO e AMAL, 2014; OURA, ZILBER e LOPES, 2016).

O modelo proposto pelos autores, conhecido como modelo de Uppsala (U-Model), evidencia também a perspectiva sequencial de processo de internacionalização. A investigação tomou por base quatro empresas cuja característica comum é o padrão linear do desenvolvimento de suas operações internacionais. O modelo é baseado no desenvolvimento do conhecimento e comprometimento crescente no país estrangeiro.

Dessa forma, foram evidenciados quatro estágios: exportação esporádica não regular; exportações por meio de representantes independentes; exportações diretas; e implantação comercial no país estrangeiro.

Outro escopo importante do estudo é a progressão geográfica dos negócios internacionais relacionada ao conceito de distância psicológica do mercado alvo, ou seja, fatores culturais e linguísticos dificultam a comunicação e o desenvolvimento do relacionamento com o cliente. Em se tratando do primeiro estágio, esse fator tem característica primordial.

Embora o modelo apresente característica sequencial, os autores admitem a possibilidade de as organizações realizarem saltos mais altos, podendo eliminar algumas etapas do processo. 
Johanson e Vahlne (1977) consideram nessas etapas quatro conceitos importantes no planejamento do processo de internacionalização baseado na abordagem de aprendizagem organizacional: conhecimento de mercado; comprometimento com o mercado; decisão de comprometimento e atividades correntes.

De acordo com isso, Barkema e Vermeulen (1998) explicam a abordagem de aprendizagem organizacional por meio da aquisição de ativos, sejam eles tangíveis ou intangíveis ou por meio da aprendizagem imitativa, quando a empresa consegue observar o que outra empresa faz para conseguir desenvolver bons negócios no mercado externo.

A aprendizagem organizacional por meio de ativos intangíveis, notadamente pautada na experiência dos indivíduos, remete à teoria de inovação, que considera o papel dos executivos como observadores participantes do processo, ou seja, obtém uma série de informações necessárias tendo por base a experiência do indivíduo.

Sob a perspectiva comportamental, Reid (1981), ao observar o processo de internacionalização do ponto de vista da inovação, também corrobora alguns preceitos importantes da abordagem da Escola de Uppsala.

\section{MODELO DE INOVAÇÃO - REID (1981) E CZINKOTA E JOHNSTON(1985)}

O Modelo de inovação ("Modelo I") abordado por Reid (1981) e Czinkota e Johnston (1985) focaliza o processo de internacionalização sob a perspectiva da inovação. Nesse caso, a internacionalização trata-se de um processo sequencial de aprendizado organizacional por meio da implementação de novas estratégias, considerando distintos níveis de comprometimento com os negócios internacionais.

Logo, o modelo é caracterizado pela aplicação de recurso gradual e incremental, já que o novo mercado é uma alternativa inovadora que requer planejamento e reconhecimento das atividades no exterior.

A inovação, à luz das empresas de pequeno porte, traduz, por meio de muitas ações, o comportamento do indivíduo à frente da empresa: o exportador. Dessa forma, o modelo se propõe também a observar as capacidades da firma tendo por base características pessoais dos executivos, demonstrando que incrementos de investimentos às exportações se dariam em virtude da percepção por parte desse indivíduo sobre os resultados auferidos no mercado internacional.

Em relação aos aspectos de inovação, tendo como ponto de vista as capacidades organizacionais, Teece (1997a) estabelece que o custo de transação da organização em negócios internacionais pressupõe sua eficiência operacional, estratégica e as condições do país anfitrião.

Na abordagem comportamental, a distância psíquica traz grande contribuição em relação ao processo de internacionalização bem como à dinâmica do posicionamento da firma diante das condições do comprador-vendedor.

\section{A DISTÂNCIA PSÍQUICA E A INTERAÇÃO COMPRADOR-VENDEDOR - HALLEN E WIEDERSHEIM- PAUL (1979)}

De acordo com esta proposta teórica, existe uma distância mental e geográfica entre as empresas compradora e vendedora de países distintos. Essas duas dimensões podem causar dificuldades em diferentes fluxos às organizações envolvidas no processo (HALLEN e WIEDERSHEIM-PAUL, 1979). Os autores explicam que a internacionalização de empresa ocorre geralmente de maneira gradual. Assim, além das condições geográficas, deve-se levar em conta o posicionamento psíquico para o estabelecimento de uma relação comercial de fluxo eficiente.

O conceito de distância psíquica foi desenvolvido pela Escola Nórdica de Negócios Internacionais e tem como principais norteadores: o nível de desenvolvimento dos países; o nível educacional dos países; as práticas de negócios e linguagem. Os autores defendem que, para que os negócios funcionem de forma satisfatória, faz-se necessário que o nível de desenvolvimento econômico e educacional dos países encontre-se em um patamar mínimo. De acordo com Child e Rodrigues (2010), é necessário, dentre outros fatores, o desenvolvimento de uma relação de confiança interorganizacional. 
Escolas teóricas do processo de internacionalização: uma visão epistemológica
Lúcia de Fátima Lúcio Gomes da Costa | Miguel Eduardo Moreno Añez Anderson Luiz Rezende Mol | Thiago dos Santos Azevedo Damasceno

Segundo esse modelo, países de mesmo nível educacional e desenvolvimento econômico têm maior facilidade de se relacionar comercialmente do que países de realidades "distantes". Desse modo, o desenvolvimento de diferentes distâncias psíquicas é um processo dinâmico e contínuo. Para tanto, os autores elaboraram uma proposta que contempla três estágios para o estabelecimento de um fluxo eficiente entre as organizações: a) pré-contrato, ou seja, período destinado ao reconhecimento da realidade do parceiro comercial; b) internação inicial, no qual são desenvolvidas as primeiras operações; e c) estágio de interação maduro, fase na qual as empresas já desenvolveram uma relação de confiança significativa.

O Quadro 1 apresenta um resumo das teorias das escolas do processo de internalização e como cada conteúdo foi construído levando em conta as bases do conhecimento. $O$ intuito de reunir essas teorias sob o ponto de vista dos seus preceitos teóricos é apresentar pontos de convergências dessas construções. Não há necessariamente uma sequência na construção teórica, porém há pontos comuns em relação às abordagens teóricas e metodológicas tomadas como orientação para construção do conhecimento, conforme explicado ao longo desta seção.

Quadro 1

Escolas do Processo de Internacionalização

\begin{tabular}{|c|c|c|c|c|c|c|}
\hline Autor/Obra & $\begin{array}{c}\text { Teoria e } \\
\text { abordagem }\end{array}$ & Objetivo Geral & Metodologia & $\begin{array}{c}\text { Variáveis/ } \\
\text { Dimensões em } \\
\text { Análise }\end{array}$ & Contribuição Teórica & Base Teórica \\
\hline $\begin{array}{l}\text { VERNON, } \\
\text { R. (1966). } \\
\text { International } \\
\text { Investment and } \\
\text { International Trade } \\
\text { in the Product } \\
\text { Cycle }\end{array}$ & $\begin{array}{l}\text { Teoria do Ciclo do } \\
\text { Produto }\end{array}$ & $\begin{array}{l}\text { Analisar o } \\
\text { processo de } \\
\text { internacionalização } \\
\text { das firmas de } \\
\text { acordo com o } \\
\text { ciclo de vida dos } \\
\text { produtos }\end{array}$ & $\begin{array}{l}\text { Fonte secundária } \\
\text { (estatística } \\
\text { descritiva) }\end{array}$ & $\begin{array}{l}\text { Ciclo de: } \\
\text { importação, } \\
\text { produção e } \\
\text { exportação dos } \\
\text { EUA, países } \\
\text { concorrentes e } \\
\text { países menos } \\
\text { desenvolvidos }\end{array}$ & $\begin{array}{l}\text { Dependendo do nível } \\
\text { de maturidade da } \\
\text { indústria, o processo } \\
\text { de importação seguido } \\
\text { por produção e } \\
\text { amadurecimento do } \\
\text { produto e exportação } \\
\text { ocorre de forma mais } \\
\text { rápida. O processo } \\
\text { de exportação deve } \\
\text { ocorrer à medida } \\
\text { que a indústria de } \\
\text { determinado país } \\
\text { também já tenha um } \\
\text { bom nível de produção } \\
\text { em escala global }\end{array}$ & $\begin{array}{l}\text { Erik Hoffmeyer, } \\
1958\end{array}$ \\
\hline $\begin{array}{l}\text { BUCKLEY, P. J.; } \\
\text { CASSON, M. C. } \\
\text { (1998). Analysing } \\
\text { foreign market } \\
\text { entry strategies: } \\
\text { extendind the } \\
\text { internalization } \\
\text { approach }\end{array}$ & $\begin{array}{l}\text { Teoria das } \\
\text { Operações } \\
\text { Internacionais }\end{array}$ & $\begin{array}{l}\text { Explicar e prever } \\
\text { os métodos de } \\
\text { atendimento do } \\
\text { mercado por parte } \\
\text { das empresas } \\
\text { multinacionais }\end{array}$ & Abordagem teórica & $\begin{array}{l}\text { Localização das } \\
\text { plantas produtivas } \\
\text { e a propriedade da } \\
\text { produção }\end{array}$ & $\begin{array}{l}\text { Um mercado nacional } \\
\text { pode ser atendido } \\
\text { de quatro maneiras } \\
\text { principais: por } \\
\text { empresas domésticas, } \\
\text { por subsidiárias de } \\
\text { multinacionais, por } \\
\text { empresas nacionais que } \\
\text { comercializam produtos } \\
\text { importados e por } \\
\text { importação direta de } \\
\text { multinacionais }\end{array}$ & Vernon, 1966 \\
\hline $\begin{array}{l}\text { DUNNING, J. H. } \\
\text { (1980). Toward } \\
\text { an eclectic theory } \\
\text { of international } \\
\text { production: some } \\
\text { empirical tests }\end{array}$ & $\begin{array}{l}\text { Teoria do } \\
\text { Paradigma do } \\
\text { Eclético }\end{array}$ & $\begin{array}{l}\text { Analisar o } \\
\text { modelo da teoria } \\
\text { eclética tendo a } \\
\text { localização como } \\
\text { determinante }\end{array}$ & $\begin{array}{l}\text { Análise } \\
\text { multivariada }\end{array}$ & $\begin{array}{l}\text { Características } \\
\text { próprias da } \\
\text { empresa; } \\
\text { características } \\
\text { específicas do país; } \\
\text { internalização }\end{array}$ & $\begin{array}{l}\text { As variáveis observadas } \\
\text { têm significância } \\
\text { em relação à } \\
\text { internacionalização de } \\
\text { empresas americanas e } \\
\text { o potencial exportador } \\
\text { tem maior importância } \\
\text { para países menos } \\
\text { desenvolvidos }\end{array}$ & $\begin{array}{l}\text { Vernon, 1966; } \\
\text { Buckley e } \\
\text { Casson, } 1976\end{array}$ \\
\hline
\end{tabular}


Escolas teóricas do processo de internacionalização: uma visão epistemológica
Lúcia de Fátima Lúcio Gomes da Costa | Miguel Eduardo Moreno Añez Anderson Luiz Rezende Mol| Thiago dos Santos Azevedo Damasceno

Continuação

\begin{tabular}{|c|c|c|c|c|c|c|}
\hline Autor/Obra & $\begin{array}{c}\text { Teoria e } \\
\text { abordagem }\end{array}$ & Objetivo Geral & Metodologia & $\begin{array}{c}\text { Variáveis/ } \\
\text { Dimensões em } \\
\text { Análise }\end{array}$ & Contribuição Teórica & Base Teórica \\
\hline $\begin{array}{l}\text { JOHANSON, } \\
\text { J.; VAHLNE, J. } \\
\text { E. (1977). The } \\
\text { Internationalization } \\
\text { Process of the } \\
\text { Firm - A Model } \\
\text { of Knowledge } \\
\text { Development } \\
\text { and Increasing } \\
\text { Foreign Market } \\
\text { Commitments }\end{array}$ & $\begin{array}{l}\text { O processo de } \\
\text { Internacionalização } \\
\text { da Escola Nórdica } \\
\text { de Uppsala }\end{array}$ & $\begin{array}{l}\text { Compreender } \\
\text { o processo de } \\
\text { internacionalização } \\
\text { da firma através } \\
\text { de aspectos } \\
\text { comportamentais } \\
\text { que traduzem o } \\
\text { fenômeno como } \\
\text { gradual }\end{array}$ & $\begin{array}{l}\text { Baseado em } \\
\text { estudos empíricos } \\
\text { de pesquisas de } \\
\text { negócios da Escola } \\
\text { de Upsalla }\end{array}$ & $\begin{array}{l}\text { Conhecimento, } \\
\text { distancia psíquica, } \\
\text { padrão de } \\
\text { decisão, grau de } \\
\text { internacionalização }\end{array}$ & $\begin{array}{l}\text { A internacionalização } \\
\text { é um fenômeno } \\
\text { gradual, que assume } \\
\text { basicamente quatro } \\
\text { estágios: exportação } \\
\text { indireta, exportação } \\
\text { direta, joint venture } \\
\text { internacional e } \\
\text { investimento direto no } \\
\text { país estrangeiro- IDE }\end{array}$ & $\begin{array}{l}\text { Vernon, 1966; } \\
\text { Hallén e } \\
\text { Weidersheim- } \\
\text { Paul, } 1979\end{array}$ \\
\hline $\begin{array}{l}\text { CZINKOTA. M. R. } \\
\text { (1985). Export } \\
\text { Development } \\
\text { Strategies.; REID. S. } \\
\text { (1981). Decision- } \\
\text { marker and } \\
\text { export and market } \\
\text { expansion }\end{array}$ & $\begin{array}{l}\text { Modelo de } \\
\text { Inovação }\end{array}$ & $\begin{array}{l}\text { Compreender } \\
\text { o processo de } \\
\text { internacionalização } \\
\text { por meio de } \\
\text { estratégias } \\
\text { incrementais de } \\
\text { inovação }\end{array}$ & $\begin{array}{l}\text { Análise } \\
\text { multivariada }\end{array}$ & $\begin{array}{l}\text { Inovação, } \\
\text { empreendedorismo } \\
\text { e recursos }\end{array}$ & $\begin{array}{l}\text { O modelo se propõe } \\
\text { também a observar } \\
\text { as características da } \\
\text { firma por meio das } \\
\text { características pessoais } \\
\text { dos executivos, } \\
\text { demonstrando que } \\
\text { incrementos de } \\
\text { investimentos às } \\
\text { exportações se dariam } \\
\text { em razão da percepção } \\
\text { sobre esse indivíduo a } \\
\text { respeito dos resultados } \\
\text { auferidos no mercado } \\
\text { internacional }\end{array}$ & $\begin{array}{l}\text { Chandler, 1962; } \\
\text { Dunning, 1980; } \\
\text { Johanson e } \\
\text { Vahlne, } 1977\end{array}$ \\
\hline $\begin{array}{l}\text { HALLÉN, L.; } \\
\text { WIEDERSHEIM- } \\
\text { PAUL, F. (1979). } \\
\text { Psychic distance } \\
\text { and buyer-seller } \\
\text { interaction }\end{array}$ & $\begin{array}{l}\text { A distância } \\
\text { psíquica e } \\
\text { a interação } \\
\text { comprador- } \\
\text { vendedor }\end{array}$ & $\begin{array}{l}\text { Analisar os } \\
\text { aspectos que } \\
\text { influenciam } \\
\text { a distância } \\
\text { geográfica } \\
\text { e psíquica } \\
\text { nos negócios } \\
\text { internacionais }\end{array}$ & $\begin{array}{l}\text { Survey fonte } \\
\text { secundária } \\
\text { (estatística } \\
\text { descritiva) }\end{array}$ & $\begin{array}{l}\text { Estágio de pré- } \\
\text { contato, interação } \\
\text { inicial e estágio } \\
\text { pré-maduro }\end{array}$ & $\begin{array}{l}\text { Existe uma distância } \\
\text { entre organizações } \\
\text { vendedoras e } \\
\text { organizações } \\
\text { compradoras, ambas } \\
\text { no sentido geográfico } \\
\text { e mental. Há também } \\
\text { distâncias nas duas } \\
\text { dimensões e entre } \\
\text { atores pertencentes à } \\
\text { mesma organização. } \\
\text { Essas distâncias causam } \\
\text { dificuldades para os } \\
\text { diferentes fluxos entre } \\
\text { comprador e vendedor. }\end{array}$ & $\begin{array}{l}\text { Burenstam- } \\
\text { Linder, } 1961\end{array}$ \\
\hline
\end{tabular}


Escolas teóricas do processo de internacionalização: uma visão epistemológica
Lúcia de Fátima Lúcio Gomes da Costa | Miguel Eduardo Moreno Añez Anderson Luiz Rezende Mol | Thiago dos Santos Azevedo Damasceno

Continuação

\begin{tabular}{|c|c|c|c|c|c|c|}
\hline Autor/Obra & $\begin{array}{c}\text { Teoria e } \\
\text { abordagem }\end{array}$ & Objetivo Geral & Metodologia & $\begin{array}{l}\text { Variáveis/ } \\
\text { Dimensões em } \\
\text { Análise }\end{array}$ & Contribuição Teórica & Base Teórica \\
\hline $\begin{array}{l}\text { ROOT, F. R. (1994). } \\
\text { Entry Strategies for } \\
\text { the international } \\
\text { Markets }\end{array}$ & Modos de Entrada & $\begin{array}{l}\text { Descrever e } \\
\text { analisar os modos } \\
\text { de ingresso } \\
\text { no mercado } \\
\text { internacional }\end{array}$ & Abordagem teórica & $\begin{array}{l}\text { Entradas de } \\
\text { exportação, } \\
\text { contratual e de } \\
\text { investimento }\end{array}$ & $\begin{array}{l}\text { A decisão sobre os } \\
\text { modos de entrada em } \\
\text { mercados externos deve } \\
\text { levar em consideração } \\
\text { fatores internos e } \\
\text { externos à empresa. } \\
\text { Os fatores internos } \\
\text { são relacionados } \\
\text { à característica } \\
\text { do produto a ser } \\
\text { comercializado e ao } \\
\text { comprometimento } \\
\text { financeiro da empresa. } \\
\text { Já os fatores externos à } \\
\text { empresa são referentes } \\
\text { ao mercado do país- } \\
\text { alvo, ambiente de } \\
\text { negócios, fatores de } \\
\text { produção entre outros. }\end{array}$ & $\begin{array}{l}\text { Vernon, } \\
\text { 1966; Bucley e } \\
\text { Dunning, } 1976\end{array}$ \\
\hline $\begin{array}{l}\text { OVIATT, B.M.; } \\
\text { MCDOUGALL, P.P. } \\
\text { (1994). Toward } \\
\text { a theory of } \\
\text { international new } \\
\text { ventures }\end{array}$ & $\begin{array}{l}\text { The Born Global } \\
\text { Firm }\end{array}$ & $\begin{array}{l}\text { Descrever } \\
\text { e analisar o } \\
\text { fenômeno da } \\
\text { internacionalização } \\
\text { por meio de várias } \\
\text { perspectivas } \\
\text { teóricas }\end{array}$ & Abordagem teórica & $\begin{array}{l}\text { Custo de } \\
\text { transação; } \\
\text { localização; } \\
\text { estrutura e } \\
\text { governança; } \\
\text { recursos raros }\end{array}$ & $\begin{array}{l}\text { As escolas da } \\
\text { internacionalização } \\
\text { passam por mudança de } \\
\text { paradigma em relação } \\
\text { à análise de empresas } \\
\text { multinacionais e há uma } \\
\text { tendência de mudança } \\
\text { nos parâmetros das } \\
\text { análises teóricas }\end{array}$ & $\begin{array}{l}\text { Chandler, 1962; } \\
\text { Dunning, 1980; } \\
\text { Johanson e } \\
\text { Vahlne, } 1977\end{array}$ \\
\hline $\begin{array}{l}\text { KNIGHT, G.A; } \\
\text { CAVUSGIL, S.T. } \\
\text { (2004). Innovation, } \\
\text { organizational } \\
\text { capabilities and } \\
\text { the born-global } \\
\text { firm }\end{array}$ & & $\begin{array}{l}\text { Analisar e } \\
\text { compreender a } \\
\text { internacionalização } \\
\text { precoce da firma }\end{array}$ & $\begin{array}{l}\text { Survey (análise } \\
\text { multivariada) }\end{array}$ & $\begin{array}{l}\text { Orientação para } \\
\text { empreendedorismo } \\
\text { internacional, } \\
\text { orientação } \\
\text { para mercado } \\
\text { internacional, } \\
\text { competência } \\
\text { tecnólogica global, } \\
\text { produtos únicos, } \\
\text { focos de qualidade, } \\
\text { competência } \\
\text { para distribuição } \\
\text { internacional, } \\
\text { performance } \\
\text { em mercados } \\
\text { internacionais }\end{array}$ & $\begin{array}{l}\text { Aspectos como } \\
\text { capacidades } \\
\text { internas pautadas na } \\
\text { inovação aumentam } \\
\text { a performace das } \\
\text { empresas born global. } \\
\text { O crescimento dessas } \\
\text { empresas refletem um } \\
\text { novo paradgma antes } \\
\text { observado apenas na } \\
\text { realidade de grandes } \\
\text { coorporações }\end{array}$ & $\begin{array}{l}\text { Penrose, 1959; } \\
\text { Shumpeter, } \\
\text { 1949; Oviatt e } \\
\text { McDougal, } 1994\end{array}$ \\
\hline \multicolumn{2}{|c|}{ Fenômeno Organizacional } & \multicolumn{2}{|c|}{ Processo Organizacional } & \multicolumn{3}{|c|}{ Estratégia Organizacional } \\
\hline
\end{tabular}

Fonte: Adaptado de Costa e Añez (2013). 
O quadro apresentado revela que o caminho teórico e pragmático seguido pelo fenômeno da internacionalização vai além dos aspectos econômicos ou comportamentais de suas abordagens. O que se percebe é que o processo de internacionalização tem sido incorporado à realidade dos negócios internacionais, mesmo que a firma atue apenas no país anfitrião. Isso quer dizer que é possível considerar que o processo de internacionalização passou a ser mais que uma estratégia para garantia de vantagem competitiva.

A internacionalização (e não processo) é parte da natureza da estratégia organizacional. Assim, as empresas nascidas globais sinalizam para a mudança paradigmática quanto ao entendimento de dois constructos importantes nos estudos em administração: estratégia internacional e processo de internacionalização. Há uma convergência teórica a indicar que essas matérias devem ser vistas como estratégia organizacional, uma vez que negócios internacionais fazem parte das demandas na competição na arena global.

De um modo geral, tal teoria com abordagens econômicas e comportamentais converge para a compreensão de que o êxito no processo de internacionalização depende de características próprias das capacidades organizacionais da firma, bem como das condições ambientais onde ela está inserida. Esses preceitos permitem perceber uma quebra paradigmática em relação a estudos econômicos sobre as vantagens comparativas e introduzem a internacionalização como um fenômeno pautado nas vantagens competitivas.

\section{ANÁLISE EPISTEMOLÓGICA DA INTERNACIONALIZAÇÃO: DAS ESCOLAS DO PROCESSO DE INTERNACIONALIZAÇÃO A GLOBAL BORN FIRM}

A partir da década de 70, o processo de internacionalização de empresa é um dos fenômenos mais estudados nas pesquisas sobre estratégias internacionais, em virtude da grande contribuição teórica apresentada pela escola nórdica de Uppsala. Antes, porém, de essas pesquisas tomarem expressão representativa da internacionalização, já se observavam mudanças paradigmáticas no entendimento dos fenômenos organizacionais.

Não é possível dissociar a análise sobre o processo de internacionalização dos estudos acerca de estratégia organizacional; esta se encontra diretamente atrelada à sua origem teórica: as escolas da administração, desde administração científica até teoria do sistema.

O que se percebe é que, para se aprofundar em um fenômeno organizacional, é necessário conhecer a trajetória histórica, contextual e teórica que o gerou (HABERMAS, 1982), a fim de reconhecer as bases desse conhecimento. De acordo com isso, essa seção dedica-se a esclarecer o conceito e a trajetória etimológica do conhecimento produzido na ciência em relação à internacionalização de empresas.

A Teoria Geral da Administração é apresentada na maioria dos cursos de graduação em Administração como a geração de um conhecimento linear. De forma geral, apresenta-se o início da história das escolas da administração com a administração científica de Taylor, Fayol e Ford (abordam a perspectiva do preço econômico e produtivista da produção em larga escala), que bem traduzia o contexto histórico da época pautado na revolução industrial. É observável que as obras desenvolvidas pelos autores há descrição de um novo paradigma pautado nas condições históricas que viabilizavam não só uma mudança significativa no sistema de produção como no padrão da própria sociedade (COSTA e AÑEZ, 2013).

Até esse momento, a construção dessas teorias em administração passa por um processo incremental não só do ponto de vista da própria criação do conhecimento, mas principalmente por esse conhecimento gerado ser reflexo de um contexto histórico direcionado para sua construção. Assim, a dinâmica da própria organização desenhava a necessidade de novas demandas teóricas que, por sua vez, descreviam as novas formas de gestão, que para Popper (1980), o princípio da verificabilidade e falseabilidade em uma teoria, ou seja, que o significado de uma proposição está relacionado diretamente aos dados empíricos que resultam de sua observação, e que, uma vez existentes, dão veracidade à proposição.

Com base na teoria dos sistemas, observou-se que, na arena de discussão, não mais se tratava dos aspectos internos e organizacionais focando em estrutura e produção, mas, sim, da relação que a organização como estrutura estabelecida tinha com seu ambiente e que dinâmica poderia promover sua eficiência estratégica, de forma a alcançar novos mercados e garantir o 
consumo. Nessa perspectiva, a teoria contingencial surge como um novo postulado teórico tendo como base a observação de aspectos voltados para a estratégia organizacional (COSTA e AÑEZ 2014).

A aplicação do conceito de estratégia tem sua origem em práticas militares, mas é em administração que, a partir da década de 50, torna-se uma referência teórica. Penrose (1959), com a teoria do crescimento da firma, e Chandler (1962), por meio da teoria contingencial, discutiam a questão da relação da empresa com o mercado observando a tecnologia ou a inovação tecnológica como variável de análise que possibilitaria o melhor desempenho mercadológico da empresa.

Essa mudança teórica também considera aspectos históricos ocorridos na época, como o pós-guerra, que trouxe um direcionamento das nações. A produção bélica deixa de ser a prioridade e passa a desenvolver perspectivas voltadas para o mercado consumidor. Nesse momento, pode-se observar uma mudança no padrão de análise organizacional, que traduz não só o reflexo de demanda da sociedade, mas leva a entender a organização como um agente proativo também capaz de mudar a dinâmica da própria sociedade. A organização deixa de ser meramente reativa e passa a interagir por meio de um sistema aberto retroalimentado com o mercado e apresentar uma nova dinâmica por meio do avanço tecnológico dos seus produtos e sistemas produtivos.

Pode-se considerar esse um ponto crucial de mudança do ponto de vista pragmático e teórico da construção do conhecimento em administração. Há nitidamente uma mudança paradigmática conceitual. O paradigma sofre de uma anomalia, segundo o conceito de Kuhn (1996), pois o problema existente, acerca da internacionalização, não pode ser lido por meio das teorias do processo de internacionalização. Isso afeta as bases deste paradigma e resiste às tentativas de solução (KUHN, 1996). Nesse sentido, a proposta de que o gradualismo da Escola de Uppsala (JOHANSON e VAHLNE, 1977), revista na década de 90 (JOHANSON e VAHLNE, 1990), apresenta evidência de que a teoria já não permite o entendimento do fenômeno, pois para que a teoria seja verificada é necessário que a firma se enquadre em algumas características específicas, as quais não condizem com o contexto dinâmico de estratégias internacionais.

Porém, não se pode considerar que ocorra uma quebra total ou uma revolução científica, uma vez que os conceitos anteriormente gerados continuam como referenciais teóricos e práticos na rotina organizacional. Todavia a forma é alterada tanto da ótica da gestão organizacional quanto da perspectiva de como fazer o conhecimento científico sobre essa gestão.

Nas teorias com enfoque estratégico, não há mais a preocupação em realizar análises de caráter descritivo, respeitando os caminhos e as dinâmicas da própria empresa, mas sim em desenvolver conhecimento de caráter preditivo com o intuito de antever formas e condições que possam garantir vantagem competitiva organizacional. Isso corrobora o estudo de Penrose (1959), que prevê que as competências internas e estratégicas de uma organização poderão promover dinâmicas que lhe garantam vantagem competitiva não necessariamente vinculada às vantagens comparativas das nações. Assim, o equilíbrio econômico pode ser viabilizado pelo esforço dessas organizações (COSTA e AÑEZ, 2013).

O estudo em estratégias estabelece-se na década de 60 e 70, quando, entre outras novas abordagens e visões na ciência da administração, surge de forma mais evidente o fenômeno da internacionalização. Mais do que garantir a competitividade em seu ambiente tarefa, as empresas buscam agora garantir mercado consumidor em outras partes do mundo.

Muitas teorias foram desenvolvidas acerca do processo de internacionalização. Por meio das análises de pesquisadores da última década, foram classificadas segundo dois tipos de enfoque: o comportamental e o econômico. De uma forma geral, as teorias econômicas são construções teóricas que defendem aspectos relativos às competências internas e à devida gestão de recurso como fator preponderante para o processo de internacionalização. Dito de outro modo, as empresas, de acordo com seu posicionamento estratégico, podem se internacionalizar de uma forma direta sem que a internacionalização seja de fato um processo e sim um posicionamento. São algumas as teorias que apresentaram esse ponto de vista Teoria da Internalização (BUCKLEY e CASSON, 1998; Paradigma Eclético (DUNNING, 1980);Teoria do Ciclo de Vida do Produto (VERNON, 1966) e Teoria da Vantagem Competitiva (PORTER, 1989).

Nas discussões teóricas verificou-se que esse processo não se dá meramente pelas competências e capacidades internas da organização, uma vez que a internacionalização está intimamente ligada à formação das estratégias organizacionais. Esse padrão de formação das estratégias exige uma análise acerca do comportamento do decisor. Dessa forma, variáveis comportamentais foram o foco de análise de teorias que abordavam o empreendedorismo internacional, como: Teoria da Escola de Uppsala (JOHANSON e VALHNE, 1977, 1990); Teoria das Redes Industriais (JOHANSON e MATTSON, 1988) e o Modelo de Inovação (CZINKOTA, 1985; REID, 1981). 
Os modelos comportamentais trouxeram grandes contribuições às análises sobre a internacionalização que compreendem que as características dos decisores e dos aspectos comportamentais definem o padrão das estratégias internacionais. Além disso, dentro desse caráter comportamental, entende-se que a internacionalização é um fenômeno processual e gradual, que demanda uma série de etapas até que uma relação de negócio internacional seja considerada "madura". Apesar de algumas críticas, os modelos tiveram grande poder de verificabilidade na realidade de muitas organizações até a década de 90.

Verificou-se que, a partir de então, a dinâmica do mercado tornou-se mais frenética, o que desencadeou uma série de circunstâncias atípicas. A mudança, no início da década de 70, desencadeada pelo movimento do avanço tecnológico e dos meios de comunicação, intensifica-se com a redução do custo dos meios de transporte e o aperfeiçoamento das ferramentas de comunicação. Reflexo disso é que a nova mudança no contexto histórico e social demanda das empresas estratégias ainda mais agressivas para competir no mercado.

Ademais, muitos mercados, como o Brasil, passaram pelo processo de abertura dos portos nesse período. Assim, empresas que outrora só focavam o mercado nacional como mercado alvo, invariavelmente precisavam observar as estratégias internacionais da concorrência para se manterem competitivas, mesmo no mercado interno. Com o processo de globalização, as ferramentas produtivas das indústrias ficaram, de certa forma, equivalentes. $\mathrm{O}$ que definiria a vantagem competitiva das organizações não se dava mais em que produzir, mas sim em como produzir.

Desse modo, no processo de escoamento dessa produção, a internacionalização entra como matéria vigente. Várias teorias foram construídas para explicar o fenômeno da internacionalização de grandes empresas early mover, porém a realização de negócios no mercado internacional não é exclusiva de grandes empresas de países desenvolvidos. Na última década, vários estudos mostraram pequenas e médias empresas com recursos limitados e que vêm obtendo sucesso competitivo em seus negócios internacionais (OVIATT e MCDOUGALL, 1994; KNIGHT e CAVUSGIL, 1994.

O conceito de internacionalização passa por uma mudança paradigmática. O foco de análise deixa de ser o processo e passa a ser o fenômeno, para o qual se adota uma nomenclatura mais apropriada à sua perspectiva pragmática: as empresas born globals; que já nascem internacionalizadas. Oviatt e McDougall (1994) iniciam estudos sobre essa nova perspectiva e apresentam a importância de empresas de menor porte mas com grande poder de manobra estratégica, que já começavam muito cedo a fazer negócios internacionais.

A contribuição dos autores também foi aprimorada por meio de outros estudos nos quais se observou que inovação, conhecimento, competências e capacidades organizacionais definiam o nível de comprometimento em negócios internacionais dessas empresas (KNIGHT e CAVUSGIL, 2004; OVIATT e MCDOUGALL, 1994).

Além disso, tais empresas possuem produtos que exigem alto grau de conhecimento e especialização, assim como inovação constante. A propriedade de ativos no exterior não é uma condição essencial desses empreendimentos internacionais, uma vez que a principal preocupação está no valor agregado do produto e não nos ativos alocados no exterior (OVIATT e MCDOUGALL, 1994; KNIGHT e CAVUSGIL, 2004).

É importante destacar que, como critério de escolha para a análise epistemológica empreendida nesta pesquisa, foram identificadas teorias que abordam a internacionalização tendo como base principalmente a utilização das capacidades organizacionais como dimensão de análise.

\section{CONSIDERAÇÕES FINAIS}

O presente artigo tratou de discutir teorias importantes acerca do fenômeno "internacionalização" a fim de permitir uma construção teórica. Desse modo, os conteúdos apresentados anteriormente foram analisados de uma perspectiva epistemológica que envolve não só o caminho histórico da evolução das teorias, mas também tendo por base aspectos motivadores dos períodos vividos pela sociedade, que tiveram efeito no ambiente organizacional e, por conseguinte, nas teorias aplicadas à administração.

Assim, as estratégias internacionais, exploradas pelas abordagens econômicas e comportamentais da internacionalização, remontam a uma análise voltada para linhas de pesquisa observadas nesse tripé, aprofundando algumas categorias de análise. 
Escolas teóricas do processo de internacionalização: uma visão epistemológica
Lúcia de Fátima Lúcio Gomes da Costa | Miguel Eduardo Moreno Añez Anderson Luiz Rezende Mol | Thiago dos Santos Azevedo Damasceno

O que se observou é que as abordagens econômicas têm maior poder de explicação a respeito do fenômeno em grandes corporações, ao passo que as comportamentais explicam melhor o processo de internacionalização de pequenas e médias empresas. Ambas apresentam limites de aplicação no campo empírico. Dialogando com os aspectos da visão baseada em recursos, percebe-se que esse recorte retoma as análises estratégica e estrutural, que, para efeito desta pesquisa, em observação às terminologias da pesquisa recente, são chamadas de capacidades organizacionais.

No Paradigma Eclético de Dunning (1980), os preceitos teóricos dão ênfase aos aspectos relativos à localização, aos fatores do ambiente, considerando, assim, o efeito país. Embora os modelos sejam passíveis de crítica, essas variáveis apresentam significado nas relações de negócios internacionais e são, de certa forma, negligenciadas.

Com a mudança de paradigma na evolução do conceito do processo de internacionalização, passou-se a concebê-lo como estratégias globais desde o surgimento do empreendimento.

Por conseguinte, o referencial teórico apresentado trouxe várias abordagens a respeito de negócios internacionais envolvendo estudos que tratam diretamente ou tangenciam as capacidades organizacionais e o ambiente como fatores importantes para compreensão das estratégias internacionais. São avaliados por meio do desempenho internacional, o constructo abordado no sentido de compreender a influência das dimensões mencionadas nos resultados financeiros e estratégicos da firma segundo a percepção dos indivíduos que operam com as atividades de comércio exterior das empresas.

A evolução teórica e o surgimento de anomalias sobre o fenômeno da internacionalização abriram espaço a um ambiente fértil para construções teóricas que apresentam soluções explicativas com maior aderência ao campo empírico dos negócios internacionais. Assim, a abordagem das nascidas globais sinaliza para uma direção de evolução do fenômeno organizacional da internacionalização - antes visto como um processo - e atualmente apresenta características endógenas às estratégias da firma.

É importante salientar que o conceito de internacionalização tem sofrido mudanças não apenas teóricas, mas também do ponto de vista de sua aplicação: empresas importadoras e empresas exportadoras são dois tipos de firma internacionalizada, cujo desempenho financeiro está diretamente relacionado ao seu desempenho internacional. A mesma análise se aplica à concepção de Investimento Direto no Exterior (IDE) (ACALIN, BLANCHARD, BOLLE et al., 2016). Logo, a discussão sobre essa terminologia também é cabível em pesquisas futuras, uma vez que as fronteiras mercadológicas, financeiras e de países se confundem nas transações das empresas internacionais, multinacionais e transacionais.

Diante do exposto, percebe-se que tanto abordagens econômicas quanto comportamentais corroboram o entendimento de que a internacionalização está relacionada às características próprias das capacidades organizacionais da firma e às condições ambientais onde ela está inserida. Dito de outro modo, as vantagens competitivas da firma, desde aspectos estruturais bem como a capacidade do empreendedor, definem o padrão de competição no âmbito interno e externo das empresas. Assim, percebe-se também uma quebra paradigmática em relação a estudos econômicos sobre as vantagens comparativas. 


\section{REFERÊNCIAS}

ACALIN, J. et al. Reality Check for the Global Economy. Washington, D.C.: Peterson Institute for International Economics, 2016.

BARNEY, J. B.; HESTERLY, W. S. Administração estratégica e vantagem competitiva. São Paulo: Pearson Prentice Hall, 1991.

BIANCHI, C.; WICKRAMASEKERA, R. Antecedents of SME export intensity in a Latin American Market. Journal of Business Research. v. 69, n. 10, p. 4368-4376, 2016.

BUCKLEY, P. J.; CASSON, M. The Future of Multinational Enterprise. Londres: Macmillian, 1976.

BUCKLEY, P. J.; CASSON, M. C. Analysing foreign market entry strategies: extendind the internalization approach. Journal of International Business Studies, v. 29, n. 3, p. 539-562, 1998.

BURENSTAM LINDER S. An Essay on Trade and Transformation. Stockholm: Almqvist \& Wiksell, 1961.

CANTWELL, John. Revisiting international business theory: a capabilitiesbased theory of the MNE. Journal of International Business Studies, v. 45, n. 1, p. 1-7, 2014.

CHANDLER, A. D. Strategy and structure: chapters in the history of the American industry. Cambridge, MA: Harvard University Press, 1962.

CHILD, J.; RODRIGUES, S. B. Padrões e Motivos da Internacionalização. In: OLIVEIRA JÚNIOR, M. M. Multinacionais brasileiras. Porto Alegre: Bookman, 2010. 39-59p.

CIRERA, X.; MARIN, A.; MARKWALD, R. Explaining export diversification through firm innovation decisions: The case of Brazil. Research Policy, v. 44, n. 10, p. 1962-1973, 2015.

COSTA, L. F. LG; AÑEZ, M. E. M. Estratégias globais: evolução do conceito de internacionalização ao fenômeno global borns, uma abordagem epistemológica e perspectivas. In: COLÓQUIO INTERNACIONAL DE EPISTEMOLOGIA E SOCIOLOGIA DA CIÊNCIA DA ADMINISTRAÇÃO, 3, Florianópolis. Anais...Florianópolis: UFSC, 2013.

COSTA, L. F. L G.; AÑEZ, M. E. M. Organizações como organismos: um estudo epistemológico da teoria contingencial baseada no conhecimento e interesse. In: COLÓQUIO INTERNACIONAL DE EPISTEMOLOGIA E SOCIOLOGIA DA CIÊNCIA DA ADMINISTRAÇÃO. 3, Florianópolis. Anais...Florianópolis: UFSC, 2014.

CZINKOTA, M. R.; JOHNSTON, W. J. Exporting: does sales volume make a difference? Journal of International Business Studies, v. 14, n. 1, p. 147-153, 1985.

DUNNING, J. H. Toward an eclectic theory of international production: some empirical tests. Journal of International Business Studies, v. 11, n. 1, p. 9-31, 1980.

HOFFMEYER, E. Dollar Shortage: and the Structure of U.S. Foreign Trade. Copenhagen: Ejnar Munksgaard, 1958.

HABERMAS, J. Conhecimento e Interesse. Rio de Janeiro: Zahar, 1982.
HALLEN, L.; WIEDERSHEIM-PAUL, F. The evolution of psychic distance in international business relationships. In: HAAG, I.; WIEDERSHEIMPAUL, F. (Eds.). Between market and hierarchy. Sweden: University of Uppsala, 1979. 15-27p.

HITT, M. A. Administração estratégica. São Paulo: Pioneira Thompson Learning, 2005.

HUANG, K. E. et al. Innovation and technology creation effects on organizational performance. Journal of Business Research, v. 69, n. 6, p. 2187-2192, 2016.

JOHANSON, J.; MATTSSON, L. G. Internationalization in industrial systems - a network approach. In: HOOD, N.; VAHLNE, J-E. (Eds.). Strategies in Global Competition. New York: Croom Helm, 1988. 303-321 p.

JOHANSON, J.; VAHLNE, J. E. The internationalization process of the firm - a model of knowledge development and increasing foreign market commitments. Journal of International Business Studies, v. 8 , n. 1 , p. 23-32, 1977.

JOHANSON, J.; VAHLNE, J. E. The mechanism of internationalisation. International marketing review, v. 7, n. 4, p. 11-24, 1990.

JOHANSON, J.; WIEDERSHEIM-PAUL, F. The internationalization of the firm: four Swedish cases. The Journal of Management Studies, v. 12, n. 3, p. 305-322, 1975.

KNIGHT, G. A.; CAVUSGIL, S. T. Innovation, organizational capabilities, and the born-global firm. Journal of International Business Studies, v. 35, n. 2, p. 124-141, 2004.

KUHN, T. S. A estrutura das revoluções científicas. 4. ed. São Paulo: Perspectiva, 1996.

LOVE, J. H.; ROPER, S.; ZHOU, Y. Experience, age and exporting performance in UK SMEs. International Business Review, v. 25, n. 4, p. 806-819, 2016.

MAIS, I.; CARVALHO, L. C.; AMAL, M. Exporter networks, innovation, and performance: an institutional approach. Revista de Administração Contemporânea, v. 18, n. 5, p. 551-576, 2014.

NAVARRO-GARCÍA, A. et al. Global model of export performance: Moderator role of export department. Journal of Business Research, v. 69 , n. 5, p. 1880-1886, 2016.

OURA, M. M.; ZILBER, S. N.; LOPES, E. L. Innovation capacity, international experience and export performance of SMEs in Brazil. International Business Review, v. 25, n. 4, p. 921-932, 2016.

OVIATT, B. M.; MCDOUGALL, P. P. Toward a theory of international new ventures. Journal of International Business Studies, v. 25, n. 1, p. 45-64, 1994.

PENROSE, E. T. The theory of the growth of the firm. New York: John Wiley, 1959. 
Escolas teóricas do processo de internacionalização: uma visão epistemológica
Lúcia de Fátima Lúcio Gomes da Costa | Miguel Eduardo Moreno Añez Anderson Luiz Rezende Mol| Thiago dos Santos Azevedo Damasceno
POPPER, K. R. A lógica da investigação científica. In: POPPER, K. R. Os Pensadores. São Paulo: Abril Cultural, 1980. caps. 1-10. 3-124p.

PORTER, M. E. Competitive Advantage. New York: Free Press, 1985.

PORTER, M. E. Estratégia competitiva: técnicas para análise de indústrias e da concorrência. 7. ed. Rio de Janeiro: Campus, 1989.

PORTER, M. E (Org.). Estratégia: a busca da vantagem competitiva. Rio de Janeiro: Campos, 1998.

REID, S. D. The decision-maker and export entry and expansion. Journal of International Business Studies, v. 12, n. 2, p. 101-112, 1981.
ROOT, F. R. Entry Strategies for the international Markets. New York: Lexington Books, 1994.

SCHUMPETER, J. O Fenômeno Fundamental do Desenvolvimento Econômico. In: SCHUMPETER, J. Teoria do Desenvolvimento Econômico. Rio de Janeiro: Nova Cultural, 1949.

TEECE, D. J. Technology transfer by multinational firms: The resource cost of transferring technological know-how. The Economic Journal, v. 87, n. 346, p. $242-261,1977$ a.

VERNON, R. International investment and international trade in the product cycle. Quarterly Journal of Economics, v. 80, n. 2, p. 190-207, 1966.

Lúcia de Fátima Lúcio Gomes da Costa

Doutora em Administração pela Universidade Federal do Rio Grande do Norte (UFRN); Professor do Instituto Federal do Rio Grande do Norte - IFRN (DIATINF). E-mail: lucialucio@gmail.com

Miguel Eduardo Moreno Añez

Doutor em Administração pela Fundação Getulio Vargas (FGV EAESP); Professor Titular da Universidade Federal do Rio Grande do Norte (UFRN). E-mail: anez1957@yahoo.com.br

Anderson Luiz Rezende Mol

Doutor em Administração pela Universidade Federal de Lavras (UFLA); Professor Titular da Universidade Federal do Rio Grande do Norte (UFRN). E-mail:mol.ufrn@gmail.com

Thiago dos Santos Azevedo Damasceno

Mestrando da Universidade Federal do Rio Grade do Norte (UFRN).E-mail: thiagotos@gmail.com 